\title{
Efficacy of pulmonary rehabilitation for bronchiectasis and related factors: which patients should receive the most treatment?
}

\begin{abstract}
Introduction: Pulmonary rehabilitation (PR) is an effective approach for patients with chronic pulmonary disease, and it is also recommended for patients with bronchiectasis. The aims of the current study were to evaluate the efficacy of a multidisciplinary PR program and identify factors associated with improvement in patients with bronchiectasis.

Material and ethods: We obtained data from patients with bronchiectasis who completed our PR program which consisted of education and training regarding bronchial hygiene. Pulmonary function test results, body composition, exercise capacity, quality of life, and psychological status were assessed before and after the PR program.

Results: We enrolled 130 patients in this retrospective study. Most patients had a history of pneumonia. The Medical Research Council (MRC) dyspnea scale, incremental shuttle walking test (ISWT), endurance shuttle walking test (ESWT), St. George's Respiratory Questionnaire (SGRO), Chronic Respiratory Questionnaire (CRO), and Hospital Anxiety and Depression (HAD) scores statistically improved after the PR program (all $p<0.001)$. Improvements were similar regardless of sex, etiology, smoking status, or number of hospitalizations. Age was negatively correlated with $\triangle \operatorname{SGRO}(p=0.024, r=-0.203)$. Baseline forced expiratory volume in $1 \mathrm{~s}\left(\mathrm{FEV}_{1}\right)$ was positively correlated with $\triangle \mathrm{CRO}(\mathrm{p}=0.015, \mathrm{r}=0.213)$ and negatively correlated with $\Delta$ anxiety $(\mathrm{p}=$ $0.014, r=-0.215)$. Baseline MRC was negatively correlated with $\triangle \mathrm{MRC}(\mathrm{p}<0.001, r=-0.563)$ and $\Delta \operatorname{SGRO}(\mathrm{p}<0.001, r=$ $-0.308)$. Baseline ISWT was negatively correlated with $\Delta$ ISWT $(p=0.043, r=-0.176)$ and $\Delta$ anxiety $(p=0.007, r=-0.237)$. Baseline SGRO was negatively correlated with $\triangle \mathrm{MRC}(p=0.003, r=-0.267)$ and $\triangle S G R O(p<0.001, r=-0.648)$.

Conclusions: Our PR program is efficacious for patients with bronchiectasis regardless of sex, etiologic cause of bronchiectasis, concomitant chronic obstructive pulmonary disease, smoking status, and/or number of hospitalizations. Improvement varied among patients which highlights the need for more studies to determine which patients will benefit most from the program.
\end{abstract}

Key words: bronchiectasis, dyspnea, exercise capacity, pulmonary rehabilitation

Adv Respir Med. 2021; 89: 15-22

\section{Introduction}

Bronchiectasis is a chronic disease characterized by permanently dilated airways. Possible underlying mechanisms include inflammation, structural airway damage, impaired mucociliary clearance, and infection [1].

The main signs of bronchiectasis are dyspnea, cough, and exercise intolerance [2]. Recurrent infection, chronic respiratory symptoms, and limited exercise capacity result in a poorer quality of life [3]. Treatment requires reduction of clinical symptoms such as dyspnea and exercise intolerance in order to improve quality of life and reduce the number of recurrent infections.

Pulmonary rehabilitation (PR) is a comprehensive multidisciplinary approach for patients with chronic lung disease, functional limitation, and dyspnea. PR includes exercise training, education, behavioral modification, and components of nutritional and psychosocial support [4, 5]. Guidelines for the management of bronchiectasis highlight the importance of PR [6-9] regardless of disease severity, pulmonary function, or the findings of high-resolution computed tomography (HRCT). Although PR is an efficacious

Address for correspondence: Ipek Candemir, Atatürk Chest Disease and Surgery Research and Education Hospital, Kecioren, Ankara, Turkey; e-mail: ipekcayli@yahoo.com DOI: 10.5603/ARM.a2021.0029

Received: 29.08.2020

Copyright (C) 2021 PTChP

ISSN 2451-4934 
intervention, the factors that modulate its effects have not been determined. The aims of the current study were to evaluate the efficacy of our multidisciplinary PR program and the factors associated with improvement in patients with bronchiectasis.

\section{Methods}

\section{Study design}

This was a retrospective observational cohort study. We obtained data from patients included in the database of our PR center, which is a referral center in a tertiary chest disease hospital in the capital city of our country. We evaluated the data of patients who completed our PR program between March 2013 and March 2019. Informed consent was obtained from all patients and information about the PR program was provided before it began. The consent form stated that data regarding the parameters of interest and patient information would be recorded. Approval for this study was obtained from our hospital review board.

\section{Patient characteristics}

All diagnoses were confirmed by our chest physician who reviewed each patient's medical history, health records, physical examination results, chest radiographs, thorax HRCT scans, and pulmonary function tests. We also reviewed the genetic test results of patients with genetic disorders or immune deficiencies. Chronic obstructive pulmonary disease (COPD) was diagnosed according to the criteria of the Global Initiative for Chronic Obstructive Lung Disease (GOLD) [10].

We included patients who completed the PR program and had no missing data, had COPD, varicose and/or cystic bronchiectasis, emphysema on HRCT, and no acute infection (as confirmed by review of the medical history, serum C-reactive protein level, and chest radiography and HRCT findings). We excluded patients who had an exacerbation of disease during the PR program.

\section{PR program}

The PR program was a comprehensive, multidisciplinary, hospital-based, and supervised outpatient program. PR was performed twice per week, and the patient also completed one unsupervised home exercise session per week. The program consisted of exercise training, psychological support, nutritional support, and educational courses (on disease pathology, disease exacerbation control, medications, nutrition, bronchial hygiene, breath control techniques, energy conservation, and relaxation). The educational courses were provided by a pulmonologist, three physiotherapists, a dietician, a respiratory nurse, and a psychologist. The PR program was tailored to suit the needs of each individual patient.

Bronchial hygiene involved a series of exercises performed in a sitting position and designed to promote breathing control, thorax expansion after holding an inspired breath, and forceful expiration of the breath [11, 12]. Each patient performed these exercises before every training session for 15-20 min. Patients and caregivers were also educated about postural drainage, manually assisted thoracic-abdominal compression, and controlled coughing [11, 12]. A physiotherapist applied the techniques before a session if necessary.

The training sessions included cycle ergometry and treadmill training (15 min each), strength training of both the upper and lower extremities (5-10 $\mathrm{min})$, and breathing and relaxation therapies (15-20 min each). Patients performed these exercises for a total of 70-90 min/day. Workloads during cycling and walking were calculated based on the results of the incremental shuttle walking test (ISWT). Patients were trained at $50 \%$ of their peak workload on the cycle ergometer, and $60-85 \%$ of peak oxygen consumption $\left(\mathrm{VO}_{2}\right)$ on the treadmill. Exercise intensity was increased according to the progress of the individual patient. Strength training of the upper and lower extremities was performed according to each patient's one-repetition maximum (1RM). Each patient performed two sets at $45-50 \%$ of the 1RM, and then performed 10 repetitions per set for the first $3-5$ sessions. For the following sessions, the weight was increased to $70 \%$ of the 1 RM. Physiotherapists closely supervised the patients, and heart rate, blood pressure, and oxygen saturation $\left(\mathrm{SpO}_{2}\right)$ were monitored during the training sessions. Supplemental oxygen was administered to maintain oxygen saturation above $90 \%$ [13].

\section{Outcome measures}

Exercise capacity, quality of life, sensation of dyspnea, pulmonary function, body composition, and psychological status were recorded at baseline and immediately after the PR program. We also recorded smoking status and the number of hospitalizations in the previous year.

Exercise capacity was evaluated with the ISWT and endurance shuttle walking test (ESWT) [14]. The tests were performed according to guidelines for field walking tests [15]. The minimal 
clinically important difference (MCID) of ISWT is $47.5 \mathrm{~m} \mathrm{[16].}$

Health-related quality of life was assessed with the St. George's Respiratory Questionnaire (SGRQ) and the Chronic Respiratory Questionnaire (CRQ). A 4-point change in the SGRQ total score corresponds to the MCID (17), while the MCID of the CRQ is 0.5 points [18]. Dyspnea was assessed with the Medical Research Council (MRC) dyspnea scale.

We used a spirometer (AS-507; Minato Medical Science, Tokyo, Japan) to determine forced vital capacity (FVC), forced expiratory volume in 1s $\left(\mathrm{FEV}_{1}\right)$, and the $\mathrm{FEV}_{1} / \mathrm{FVC}$ ratio. Spirometry was performed in accordance with the guidelines of the American Thoracic Society/European Respiratory Society [19]. We used a TANITA analyzer (TBF-300A Total Body Composition Analyzer; TANITA, Tokyo, Japan) to measure bioelectrical impedance and body composition. Body mass index (BMI) and the fat-free mass index (FFMI) were calculated as weight in kilograms divided by the square of height in meters (body mass was used to calculate BMI; fat-free mass was used to calculate FFMI). Hospital Anxiety and Depression (HAD) scores were used to assess psychological status [20].

\section{Statistical analysis}

We used SPSS for Windows software (version 18.0; SPSS, Inc., Chicago, IL, USA) to perform the statistical analysis. Assuming a two-sided alpha level of 0.05 , we performed Cohen's d analysis [21] with $G^{*}$ Power 3.1.9.2 software (Heinrich-Heine-Universität, Düsseldorf, Germany) to determine that the beta level was 0.20 and the effect size was medium. We used the Shapiro-Wilk test to evaluate the distributions of the variables. Descriptive statistics are expressed as mean \pm standard deviation or median (range). Categorical variables are expressed as number and percentage (\%). Improvements in parameters were calculated by subtracting the absolute pre-PR value from the post-PR value, denoted by ' $\Delta$ '.

We compared continuous variables among groups with one-way analysis of variance or the Kruskal-Wallis test. Spearman correlation analysis was also performed. Pre-post values were analyzed with the Wilcoxon signed-rank test (for non-normally distributed data) or the paired T-test (for normally distributed data). Binary logistic regression was used to assess the association between sex and score improvement. All other associations were analyzed by regression analysis. Baseline ISWT and FEV1 were adjusted for age, sex, and BMI. $\mathrm{P}<0.05$ indicates statistical significance.

\section{Results}

We enrolled 130 patients who completed the PR program. Sixty-eight (52\%) patients were men. The mean age was $47 \pm 15$ years. Five (4\%) patients were current smokers, forty-one (31\%) were former smokers, and eighty-four (65\%) had never smoked. In total, $78(60 \%)$ patients had a history of pneumonia, 33 (24\%) had concomitant COPD, $8(6 \%)$ had a history of tuberculosis, $2(2 \%)$ had immune deficiency, 3 (2\%) had Kartagener syndrome, 4 (3\%) had primary ciliary dyskinesia, and $2(2 \%)$ had cystic fibrosis. Seventy-eight (58\%) patients had an obstruction according to the pulmonary functional test. The mean $\mathrm{FEV}_{1}$ was $42 \% \pm 19 \%$ and the mean FVC was $53 \% \pm 21 \%$ of the predicted value.

MRC, ISWT, ESWT, SGRQ, CRQ, and HAD scores were significantly higher after the PR program $(\mathrm{p}<0.001)$. The improvements exceeded the MCID values.

We also investigated the relationships of the improvements in MRC, ISWT, ESWT, SGRQ, CRQ, and HAD scores with age, sex, presence of concomitant or underlying disease, number of hospitalizations, and baseline $\mathrm{FEV}_{1}$, MRC, ISWT, and SGRQ scores/values (Figures 1-3). The improvements were not associated with sex, underlying disease, smoking status, or the number of hospitalizations in the previous year. Age was negatively correlated with $\triangle$ SGRQ $(p=0.024, r=$ -0.203). Baseline $\mathrm{FEV}_{1}$ was positively correlated with $\triangle$ CRQ ( $p=0.015, r=0.213$ ) but negatively correlated with $\Delta$ anxiety $(\mathrm{p}=0.014, \mathrm{r}=-0.215)$. Baseline MRC was negatively correlated with $\triangle$ MRC $(\mathrm{p}<0.001, \mathrm{r}=-0.563)$ and $\triangle$ SGRQ $(\mathrm{p}<$ $0.001, r=-0.308)$. Baseline ISWT was negatively correlated with $\triangle \mathrm{ISWT}(\mathrm{p}=0.043, \mathrm{r}=-0.176)$ and $\Delta$ anxiety $(\mathrm{p}=0.007, \mathrm{r}=-0.237)$. Baseline SGRQ was negatively correlated with $\triangle \mathrm{MRC}(\mathrm{p}=0.003$, $\mathrm{r}=-0.267)$ and $\triangle$ SGRQ $(\mathrm{p}<0.001, \mathrm{r}=-0.648)$.

\section{Discussion}

Multidisciplinary PR proved to be an efficacious approach for improving dyspnea, exercise capacity, quality of life, and psychological status in patients with bronchiectasis regardless of sex, etiology of bronchiectasis, presence of concomitant COPD, smoking status, and/or the number of hospitalizations in the previous year 


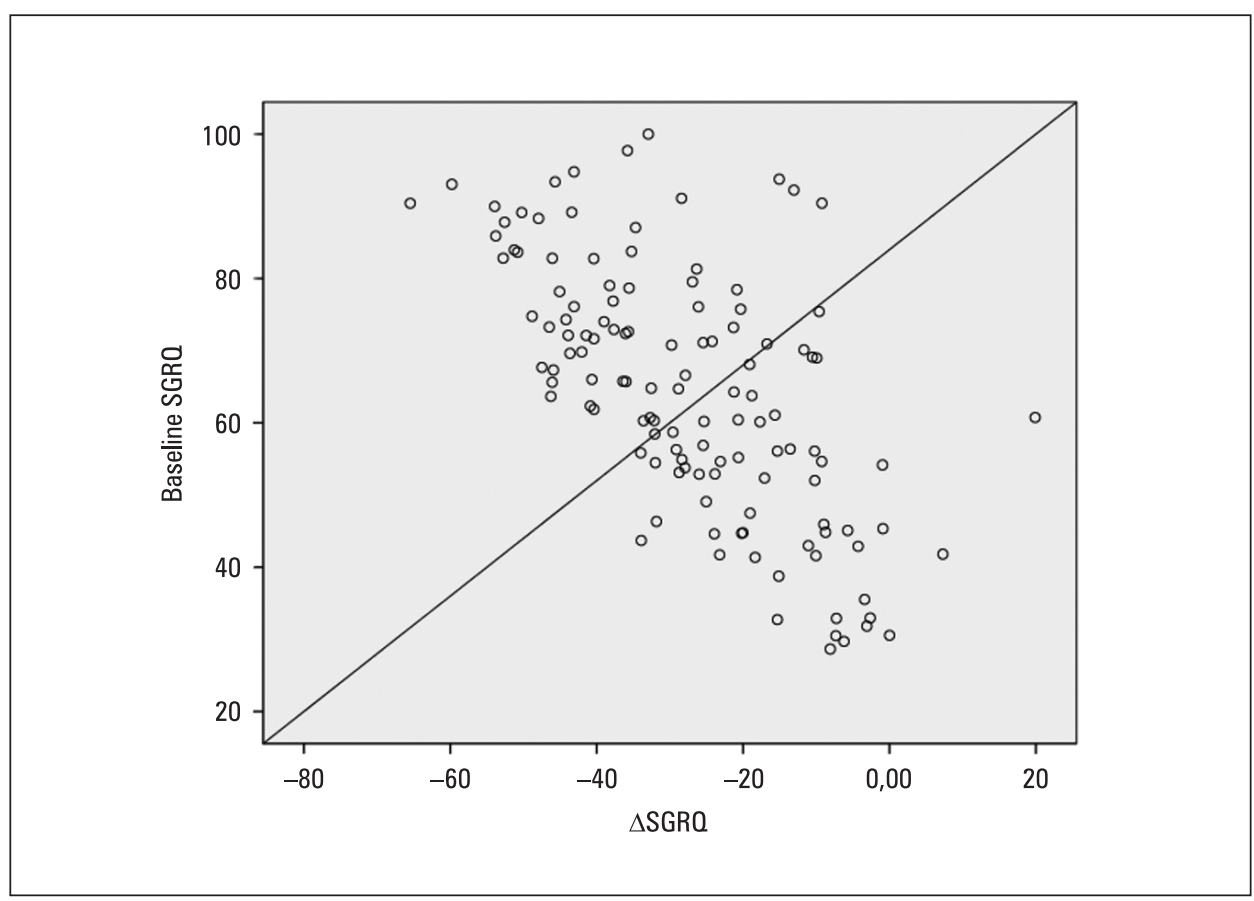

Figure 1. The relation between baseline St. George's Respiratory Questionnaire (SGRO) and $\triangle$ SGRO

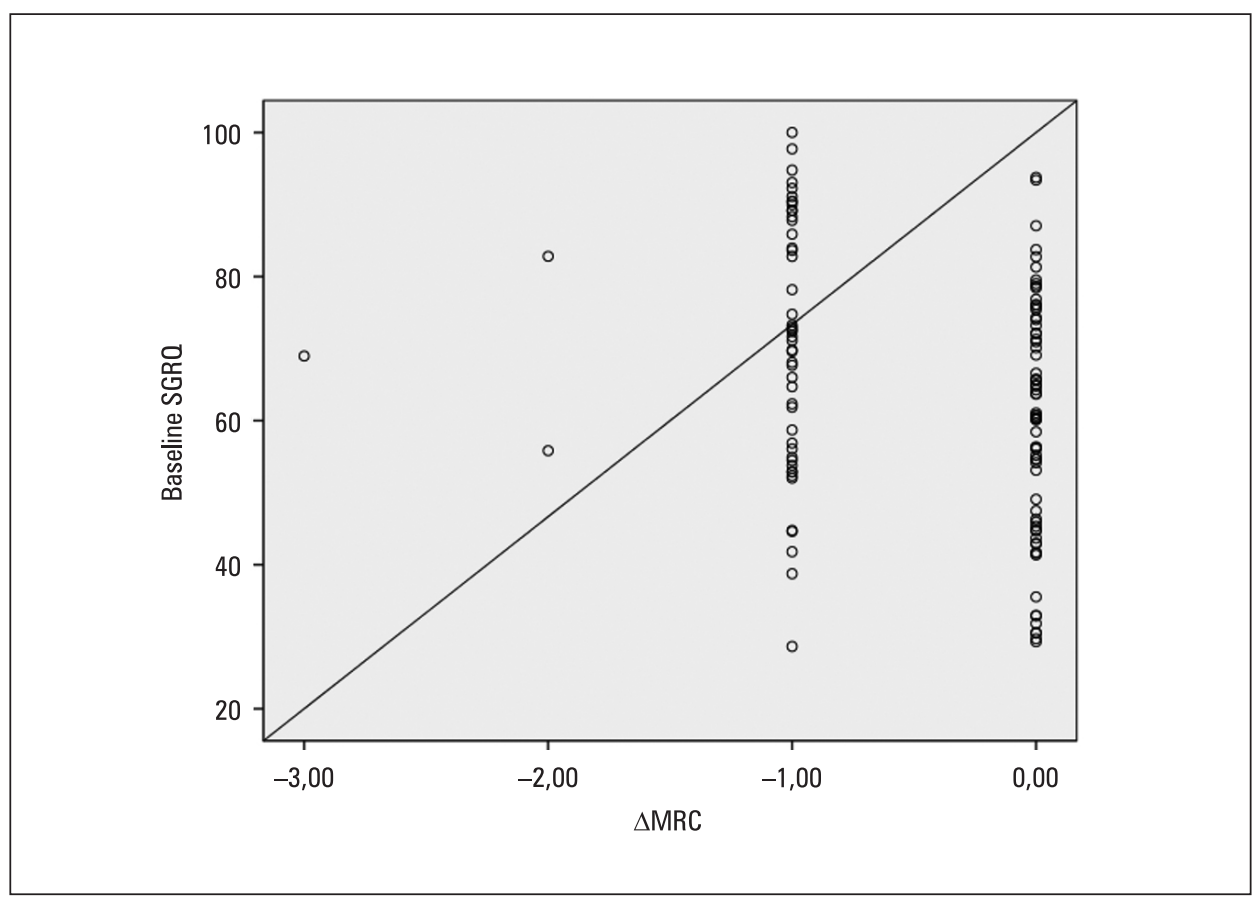

Figure 2. The relation between baseline St. George's Respiratory Questionnaire (SGRO) and $\Delta$ Medical Research Council (MRC)

(Tables 1, 2). Improvements in quality of life were greater among patients who were younger and had less severe dyspnea, better quality of life, and better $\mathrm{FEV}_{1}$ at baseline. Improvements in dyspnea were greater among patients who had less severe dyspnea and a better quality of life at baseline. Patients who had lower exercise capacity or $\mathrm{FEV}_{1}$ showed greater improvements in anxiety scores, and patients who had poorer exercise capacity showed greater improvements in exercise capacity.

Bronchiectasis is associated with a variety of common and rare diseases, some of which impact mucociliary clearance and immunity. Immune 


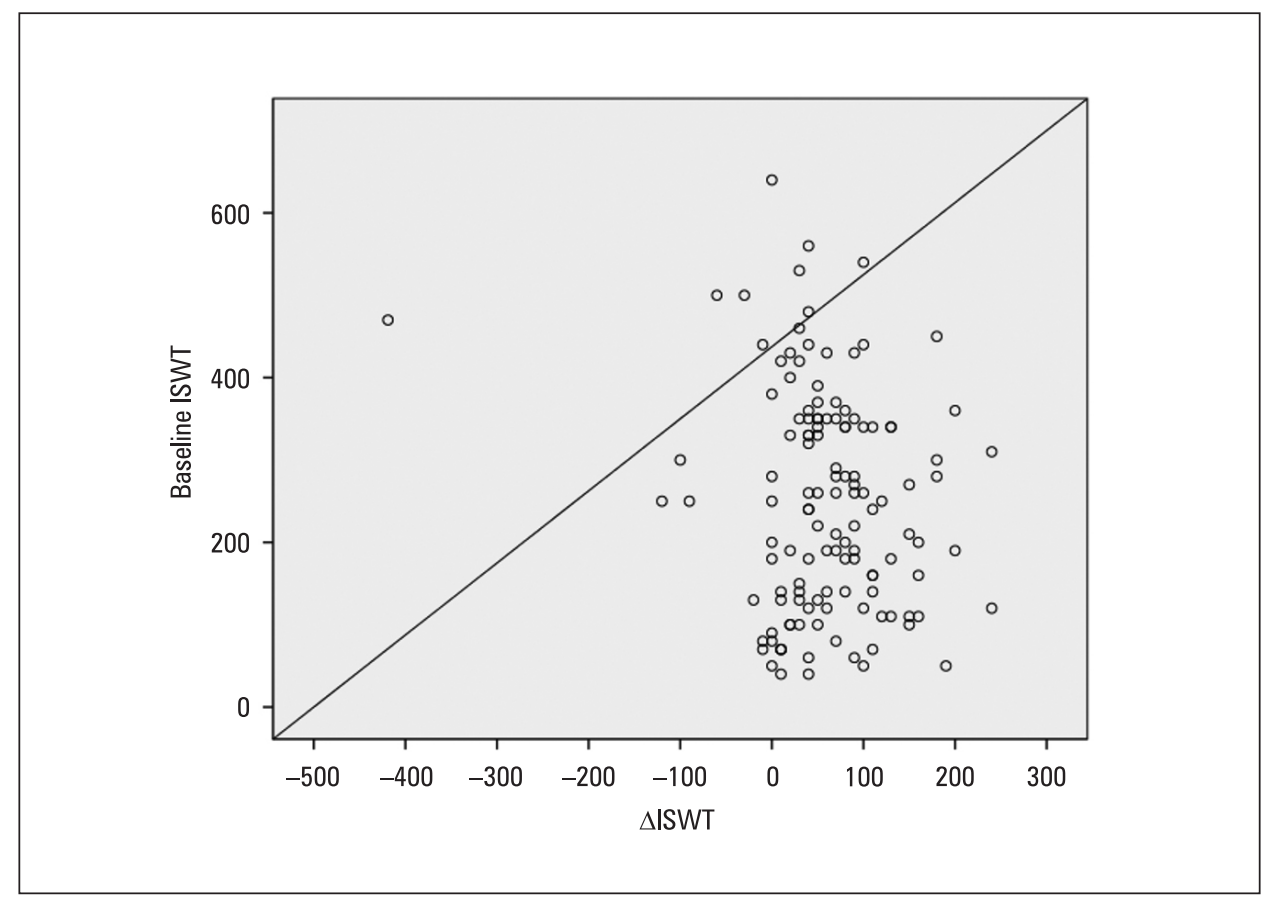

Figure 3. The relation between baseline incremental shuttle walking test (ISTW) and $\Delta$ ISWT

Table 1. Features of patients and parameters before and after PR

\begin{tabular}{|c|c|c|c|}
\hline & $\begin{array}{c}\text { Before PR } \\
\text { mean } \pm \text { SD }\end{array}$ & $\begin{array}{c}\text { After PR } \\
\text { mean } \pm \text { SD }\end{array}$ & $\mathbf{P}$ \\
\hline Age [years] & & $47 \pm 15$ & \\
\hline Current/former/never smoker & & $5(4 \%) / 41$ (31\%) / 84 (65\%) & \\
\hline Cigaratte & & $10 \pm 20(0: 90)$ & \\
\hline $\mathrm{FEV}_{1} \%$ predicted & $42 \pm 19$ & $43 \pm 19$ & 0.475 \\
\hline FVC\% predicted & $53 \pm 21$ & $53 \pm 20$ & 0.723 \\
\hline $\mathrm{FEV}_{1} / \mathrm{FVC}$ & $66 \pm 13$ & $65 \pm 14$ & 0.213 \\
\hline BMI $\left[\mathrm{kg} / \mathrm{m}^{2}\right]$ & $25 \pm 7$ & $25 \pm 6$ & 0.207 \\
\hline FFMI $\left[\mathrm{kg} / \mathrm{m}^{2}\right]$ & $18 \pm 3$ & $18 \pm 3$ & 0.313 \\
\hline MRC scale & $3 \pm 1$ & $2 \pm 1$ & $<0.001$ \\
\hline ISWT [m] & $250 \pm 137$ & $310 \pm 144$ & $<0.001$ \\
\hline ESWT [min] & $8 \pm 7$ & $13 \pm 8$ & $<0.001$ \\
\hline CRO total score & $67 \pm 16$ & $91 \pm 20$ & $<0.001$ \\
\hline SGR0-total score & $64 \pm 17$ & $37 \pm 14$ & $<0.001$ \\
\hline HAD score & $\begin{array}{l}10 \pm 2 \\
10 \pm 2\end{array}$ & $\begin{array}{l}8 \pm 2 \\
8 \pm 2\end{array}$ & $<0.001$ \\
\hline
\end{tabular}

PR — pulmonary rehabilitation; $\mathrm{FEV}_{1}$ — forced expiratory volume in 1 sec; FVC — forced vital capacity; BMI — body mass Index; FFMI — fat-free mass index; MRC — Medical Research Council; ISWT — incremental shuttle walking test; ESWT — endurance shuttle walking test; CRO — chronic respiratory questionnaire; SGRO — St. George's Respiratory Questionnaire; HAD — hospital axiety and depression

deficiency syndromes and metabolic pathologic conditions are the most common etiologies of bronchiectasis in developed countries, while bacterial and viral infections are major causes of bronchiectasis in developing countries [22].
In our study, the most common etiology was a history of pneumonia. As expected, genetic and immunologic disorders were uncommon because we only included adult patients (mean age of $47 \pm 15$ years). 
Table 2. Relation between some baseline values and improvements

\begin{tabular}{|c|c|c|c|c|c|c|c|}
\hline \multirow[b]{2}{*}{ Baseline values } & \multicolumn{7}{|c|}{$\mathbf{p} / \mathbf{r}^{*}$} \\
\hline & $\Delta \mathrm{MRC}$ & $\Delta \mathrm{ISWT}$ & $\Delta \mathrm{ESWT}$ & $\triangle \mathrm{SGRO}$ & $\triangle \mathrm{CRO}$ & $\Delta$ Anxiety & $\Delta$ Depression \\
\hline Age [years] ${ }^{* *}$ & 0.077 & 0.521 & 0.085 & $\begin{array}{c}0.024 \\
-0.203\end{array}$ & 0.875 & 0.221 & 0.093 \\
\hline $\operatorname{Sex}^{\#}$ & 0.689 & 0.882 & 0.957 & 0.585 & 0.648 & 0.079 & 0.192 \\
\hline Hospitalization ${ }^{\mathrm{f}}$ & 0.095 & 0.486 & 0.756 & 0.518 & 0.555 & 0.332 & 0.110 \\
\hline Disease $^{\S}$ & 0.220 & 0.890 & 0.651 & 0.335 & 0.135 & 0.438 & 0.997 \\
\hline Smoking status $\$$ & 0.110 & 0.491 & 0.188 & 0.312 & 0.325 & 0.250 & 0.174 \\
\hline Baseline $\mathrm{FEV}_{1}^{+}$ & 0.148 & 0.699 & 0.682 & 0.798 & $\begin{array}{l}0.015 \\
0.213\end{array}$ & $\begin{array}{r}0.014 \\
-0.215\end{array}$ & 0.318 \\
\hline Baseline MRC** & $\begin{array}{c}<0.001 \\
-0.563\end{array}$ & 0.822 & 0.488 & $\begin{array}{c}<0.001 \\
-0.308\end{array}$ & 0.106 & 0.289 & 0.358 \\
\hline Baseline ISWT $^{+}$ & 0.129 & $\begin{array}{r}0.043 \\
-0.176\end{array}$ & 0.284 & 0.932 & 0.062 & $\begin{array}{r}0.007 \\
-0.237\end{array}$ & 0.374 \\
\hline Baseline SGRO** & $\begin{array}{c}0.003 \\
-0.267\end{array}$ & 0.958 & 0.207 & $\begin{array}{c}<0.001 \\
-0.648\end{array}$ & 0.478 & 0.349 & 0.158 \\
\hline
\end{tabular}

${ }^{*}$ Correlation coefficients were given when p values were statistically significant; ${ }^{* *}$ spearmans' correlation; ${ }^{*}$ Binary logistic regression; ${ }^{\mathfrak{f}}$ Linear regression; ${ }^{\text {KKruskal-Wal- }}$ lis test; ${ }^{+}$Adjusted for age, sex, and BMI using linear regression analysis

$\mathrm{FEV}_{1}$ — forced expiratory volume in $1 \mathrm{sec}$; MRC — Medical Research Council; ISWT — incremental shuttle walking test; SGRO — St. George's Respiratory Questionnaire

Bronchiectasis can coexist with other lung diseases such as COPD. In our study, 33 (24\%) patients had COPD. In another study from our country, the mean age of 304 patients with bronchiectasis was $56 \pm 25$ years; $65.8 \%$ of patients were non-smokers and $47.4 \%$ showed obstruction on pulmonary function tests [23]. In our study, $65 \%$ of the patients had never smoked and $58 \%$ had an obstruction. Obstruction may be associated with concomitant COPD, and bronchiectasis itself may also cause obstruction.

The main clinical manifestations of bronchiectasis are chronic cough, sputum production, dyspnea, fatigue, anxiety, depression, and functional limitations that negatively impact quality of life [1]. In our study, patients had dyspnea, limited exercise capacity, poor quality of life, borderline anxiety, and depression. Several studies have shown the positive impacts of PR, especially on exercise capacity and quality of life [24-28]. Recent guidelines also emphasize PR in the management of bronchiectasis [6-8]. In our study, after completion of the multidisciplinary PR program, patients showed significant improvements in dyspnea, exercise capacity, quality of life, and psychological status. It is important to note that these improvements exceeded the MCID values. In a recent review, ISWT increased from 52 to $82 \mathrm{~m}$ in patients with bronchiectasis after PR [25]. In our study, ISWT increased by $60 \mathrm{~m}$. In another study, the total CRQ score increased by 12.8 after completion of a multidisciplinary PR program [29]. In our study, the total CRQ score increased by 24 points. Other studies may have enrolled patients with significantly different baseline CRQ scores and exercise capacities although, similar to our study, another recent study reported that HAD scores changed in response to $\mathrm{PR}$ in patients with bronchiectasis with an estimated MCID of -2 points [30].

The short and long-term outcomes of PR for patients with bronchiectasis have been evaluated in several studies of various PR programs and these studies concluded that the degree of improvement in exercise capacity was not affected by program intensity or duration [1]. Our program, which was conducted in accordance with recent guidelines, was a comprehensive, multidisciplinary, hospital-based, and supervised outpatient program where all the components were tailored to the needs of the individual patient. Education, an important component of PR programs, is an issue in patients with bronchiectasis. In a previous study, quality of life improved in patients with bronchiectasis even after they received only education [31]. A recent review asserted that education should include bronchial hygiene and breath control techniques which improve sputum expectoration, certain measures of lung function, symptoms, and quality of life [32, 33]. All airway clearance techniques showed similar clinical outcomes [31]. We believe that education about airway clearance techniques may have improved the outcomes of our patients. 
Few studies have investigated the factors predicting the efficacy of PR in patients with bronchiectasis $[24,26]$. In a recent review, most studies of patients with COPD indicated that PR can be effective for patients of any age in terms of improving exercise capacity, health status, and anxiety and depression [34, 35]. Similarly, in our study, age was not associated with improvements in exercise capacity or anxiety and depression, but it was associated with an improved quality of life. In a propensity-matched control study that compared patients with bronchiectasis to those with COPD, similar improvements in exercise, quality of life, and CRQ scores were seen [29]. In our study, dyspnea, exercise capacity, quality of life, and psychological status improved regardless of concomitant COPD. In another study, 108 patients with bronchiectasis who completed a 3-week PR program showed improvements in exercise capacity and quality of life. In this same study, male sex, baseline $\mathrm{FEV}_{1}$, vital capacity less than $70 \%$, and more than two disease exacerbations in the previous year were independent predictors of PR efficacy [27]. In another study, 41 patients with bronchiectasis underwent PR. After PR, pulmonary function, arterial blood gas levels, and 6-minute walking distance (6MWD) improved. However, they did not improve significantly, and PR outcomes were not associated with sex, bacterial colonization, or disease exacerbation [24]. In our study, sex and the number of hospitalizations were not associated with improved outcomes, and only low exercise capacity at baseline was associated with an improvement in exercise capacity. This may have been due to the enrollment of a heterogeneous group of younger patients with lower baseline exercise capacity compared to the patients enrolled in the other two studies. Similar to our findings, patients with COPD and limited exercise capacity had higher exercise capacity after PR [36, 37].

The efficacy of PR has been proven but the factors associated with beneficial outcomes and the patients that respond best have not been determined. In another study, patients with COPD and MRC grade 5 dyspnea showed smaller improvements in exercise capacity and quality of life after PR in comparison with patients with less severe dyspnea [38]. Similar to the patients in our study, patients with less severe dyspnea showed greater improvements in quality of life. In a multicenter study of patients after completion of a PR program, 2,068 patients with COPD and 49\% of predicted $\mathrm{FEV}_{1}$ were grouped according to MRC, $6 \mathrm{MWD}$, endurance time, scores on measures of performance and satisfaction, and HAD and total SGRQ scores. Patients in the "very good responder" group had more severe signs of dyspnea, more hospitalizations, and worse exercise performance, satisfaction scores, anxiety, depression, and health status [39]. In our study, improvements in quality of life were greater among patients who were younger, had less severe dyspnea, and had a better quality of life and $\mathrm{FEV}_{1}$ at baseline. Patients who had lower exercise capacity or $\mathrm{FEV}_{1}$ showed greater improvements in anxiety scores. These findings may have been due to the study design, number of patients enrolled, and exercise capacity and diagnoses thereof. Although the mechanisms underlying dyspnea and quality of life may be similar between patients with COPD and those with bronchiectasis, these mechanisms are multifactorial and other as-yet unidentified factors may exist.

A major limitation of this study was its single-center design which limits the generalizability of the results.

\section{Conclusion}

Multidisciplinary PR is an efficacious approach to improve dyspnea, exercise capacity, quality of life, and psychological status in patients with bronchiectasis regardless of sex, etiology of bronchiectasis, presence of concomitant COPD, smoking status, and the number of hospitalizations in the previous year. Improvements in quality of life and dyspnea were greater for patients who were younger, had less severe dyspnea, and had better $\mathrm{FEV}_{1}$. Improvements in quality of life, exercise capacity, and anxiety were greater for patients who had poorer exercise capacity and $\mathrm{FEV}_{1}$ at baseline. All patients with bronchiectasis should be referred for PR regardless of age, pulmonary function, exercise capacity, and quality of life because their outcomes may be improved. More studies are needed to determine which patients will likely benefit most from PR.

\section{Conflict of interest}

None declared.

\section{References:}

1. Bronchectasis monograph, Edited by Chalmers JD, Polverino E, Aliberti S, Bals R. Published by European Respiratory Society (C) 2018, www.books.ersjournals.com

2. Polverino E, Goeminne PC, McDonnell MJ, et al. European Respiratory Society guidelines for the management of adult bronchiectasis. Eur Respir J 2017; 50: 1700629.

3. Quittner AL, Marciel KK, Salathe MA, et al. A preliminary quality of life questionnaire-bronchiectasis: a patient-reported outcome measure for bronchiectasis. Chest 2014; 146: 437-448. 
4. Bolton CE, Bevan-Smith EF, Blakey JD, et al. British Thoracic Society guideline on pulmonary rehabilitation in adults. Thorax 2013; 68:1-30.

5. Spruit MA, Singh SJ, Garvey C, et al. An official American Thoracic Society/European Respiratory Societystatement: key concepts and advances in pulmonary rehabilitation. Am J Respir Crit Care Med 2013; 188: e13-e64.

6. Polverino E, Goeminne PC, McDonnell MJ, et al. European Respiratory Society guidelines for the management of adult bronchiectasis. Eur Respir J 2017; 50: 1700629.

7. Martínez-García MA, Máiz L, Olveira C, et al. Spanish Guidelines on Treatment of Bronchiectasis in Adults. Arch Bronconeumol 2018; 54: 88-98.

8. Pasteur MC, Bilton D, Hill AT. British Thoracic Society guideline for non-CF bronchiectasis. Thorax 2010; 65:Suppl. 1, i1-i58.

9. Chang AB, Bell SC, Torzillo PJ, et al. Chronic suppurative lung disease and bronchiectasis in children and adults in Australia and New Zealand: Thoracic Society of Australia and New Zealand guidelines. Med J 2015; 202: 21-23.

10. Global Initiative for Chronic Obstructive Lung Disease (GOLD) 2020 report. Avaible on https://goldcopd.org/wp-content/uploads/2019/11/GOLD-2020-REPORT

11. Nicolson CH, Holland AE, Lee AL. The Bronchiectasis Toolbox - a comprehensive website for the management of people with bronchiectasis. Med Sci 2017; 5: E13.

12. Self-Management Resources for Bronchiectasis (SMR-B). https://smr-b.com Date last accessed: February 24, 2018.

13. Garvey C, Bayles MP, Hamm LF, Hill K, Holland A, Limberg TM, Spruit MA. Pulmonary Rehabilitation Exercise Prescription in Chronic Obstructive Pulmonary Disease: Review of Selected Guidelines: An Official Statement From The American Association Of Cardiovascular And Pulmonary Rehabilitation. J Cardiopulm Rehabil Prev. 2016;36(2):75-83

14. Singh SJ, Morgan MDL, Scott S, Walters D, Hardman AE. Development of a shuttle walking test of disability in patients with chronic airways obstruction. Thorax 1992;47:1019-24.

15. Holland AE, Spruit MA, Troosters T, Puhan MA, Pepin V, Saey D, McCormack MC, et al. An official European Respiratory Society/American Thoracic Society technical standard: field walking tests in chronicrespiratory disease. Eur Respir J 2014; 44: 1428-1446

16. Singh SJ, Jones PW, Evans R, Morgan MD. Minimum clinically important improvement for the incremental shuttle walking test. Thorax 2008; 63: 775-77.

17. Jones PW. Interpreting thresholds for a clinically significant change in health status in asthma and COPD. Eur Respir J. 2002;19(3):398-404

18. Moran LA, Guyatt GH, et al. Establishing the minimal number of items for a responsive, valid, health-related quality of life instrument. J Clin Epidemiol 2001;54(6): 571-9.

19. European RS, American Thoracic Society. ATS/ ERS Statementon respiratory muscle testing. Am J Respir Crit CareMed 2002;166:518-624

20. Aydemir O, Güvenir T, Küey L, Kültür S. Reliability and Validity of the Turkish version of Hospital Anxiety and Depression Scale. Turk J Psychiatry 1997; 8:280-287.

21. Sullivan GM, Feinn R. Using Effect Size-or Why the P Value Is Not Enough. J Grad Med Educ. 2012; 4(3): 279-282.

22. Cobanoglu U, Yalcinkaya I, Er M, Isik AF, Sayir F, Mergan D. Surgery for bronchiectasis: The effect of morphological types to prognosis. Ann Thorac Med. 2011 Jan; 6(1):25-32
23. Habesoglu MA, Ugurlu AO, Eyuboglu FO. Clinical, radiologic, and functional evaluation of 304 patients with bronchiectasis. Ann Thorac Med. 2011; 6(3): 131-136.

24. van Zeller M, Mota PC, Amorim A, Viana P, Martins P, Gaspar L, Hespanhol V, Gomes I: Pulmonary rehabilitation in patients with bronchiectasis: pulmonary function, arterial blood gases, and the 6-minute walk test. J Cardiopulm Rehabil Prev 2012;32:278-283.

25. Lee AL, Hill CJ, McDonald CF, Holland AE. Pulmonary rehabilitation in individuals with non-cystic fibrosis bronchiectasis: a systematic review. Arch. Phys. Med. Rehabil. 2017; 98: 774-82.

26. Ong HK, Lee AL, Hill CJ, Holland AE, Denehy L. Effects of pulmonary rehabilitation in bronchiectasis: a retrospective study. Chron.Respir. Dis. 2011; 8: 21-30.

27. Zanini A, Aiello M, Adamo D, Cherubino F, Zampogna E, Sotgiu G, Chetta A, Spanevello A. Effects of pulmonary rehabilitation in patients with non-cystic fibrosis bronchiectasis: a retrospective analysis of clinical and functional predictors of efficacy Respiration 2015; 89: 525-33

28. O'neıll K, O'donnell AE, Bradley JM. Airway clearance, mucoactive therapies and pulmonary rehabilitation in bronchiectasis. Respirology 2019; 24: 227-237.

29. Patel S, Cole AD, Nolan CM, Barker RE. Jones SE, Kon S Cairn J, Loebinger M, Wilson R, Man W.Pulmonary rehabilitation in bronchiectasis: a propensity-matched study. Eur Respir J 2019; 53: 180-1264

30. Wynne SC, Patel S, Barker RE, Jones SE, Walsh JA, Kon SC, Cairn J, Loebinger MR, Wilson R, Man W, Nolan CM. Anxiety and depression in bronchiectasis: Response to pulmonary rehabilitation and minimal clinically important difference of the Hospital Anxiety and Depression Scale. Chronic Respiratory Disease 2019; 17: 1-9.

31. Lavery KA, O’Neill B, Parker M, et al. Expert patient self-management program versus usual care in bronchiectasis: a randomized controlled trial. Arch Phys Med Rehabil 2011; 92: 1194-1201.

32. Lee AL, Burge AT, Holland AE. Positive expiratory pressure therapy versus other airway clearance techniques for bronchiectasis. Cochrane Database Syst. Rev. 2017; 9: CD011699.

33. Lee AL, Burge AT, Holland AE. Airway clearance techniques for bronchiectasis. Cochrane Database Syst. Rev. 2015; (11): CD008351.

34. Bennett D, Bowen B, McCarthy P, Subramaniam A,O'Conno r M, Henry MT. Outcomes of pulmonary rehabilitationfor COPD in older patients: a comparative study. COPD 2017;14:170-5

35. Rochester CL. Patient assessment and selection for pulmonary rehabilitation. Respirology 2019; 24: 844-853

36. Troosters T, Gosselink R, Decramer M. Exercise training in COPD:how to distinguish responders from nonresponders. J. Cardiopulm.Rehabil. 2001; 21:10-7.

37. Plankeel JF, McMullen B, MacIntyre NR. Exercise outcomes afterpulmonary rehabilitation depend on the initial mechanism of exer-cise limitation among non-oxygen-dependent COPD patients.Chest 2005; $127: 110-6$.

38. Garrod R, Marshall J, Barley E, Jones PW. Predictors of success and failure in pulmonary rehabilitation European Respiratory Journal 2006 27: 788-794;

39. Spruit, MA, Augustin IML, Vanfleteren LE., Janssen DJA, Gaffron S, Pennings HJ, Franssen FME. Et al. Differential response to pulmonary rehabilitation in COPD: multidimensional profiling. European Respiratory Journal, 2015; 46(6): 1625-1635 